\title{
Evidence for superplasticity in a CoCrFeNiMn high-entropy alloy processed by high-pressure torsion
}

\author{
Hamed Shahmir $^{\mathrm{a}}$, Junyang $\mathrm{He}^{\mathrm{b}}$, Zhaoping Lu ${ }^{\mathrm{b}}$, Megumi Kawasaki ${ }^{\mathrm{c}}$, Terence G. Langdon ${ }^{\mathrm{a}}$ \\ ${ }^{a}$ Materials Research Group, Faculty of Engineering and the Environment, \\ University of Southampton, Southampton SO17 1BJ, UK \\ ${ }^{b}$ State Key Laboratory for Advanced Metals and Materials, University of Science and \\ Technology Beijing, Beijing 10083, People's Republic of China \\ ${ }^{c}$ Division of Materials Science and Engineering and the Research Institute of Industrial \\ Science, Hanyang University, Seoul 133-791, South Korea
}

\begin{abstract}
A CoCrFeNiMn high-entropy alloy was processed by high-pressure torsion to produce a grain size of $\sim 10 \mathrm{~nm}$ and then tested in tension at elevated temperatures from 773 to $1073 \mathrm{~K}$ using strain rates in the range from $1.0 \times 10^{-3}$ to $1.0 \times 10^{-1} \mathrm{~s}^{-1}$. The alloy exhibited excellent ductility at these elevated temperatures including superplastic elongations with a maximum elongation of $>600 \%$ at a testing temperature of $973 \mathrm{~K}$. It is concluded that the formation of precipitates and the sluggish diffusion in the HEA inhibit grain growth and contribute to a reasonable stability of the fine-grained structure at elevated temperatures. The results show the activation energy for flow matches the anticipated value for grain boundary diffusion in nickel but the strain rate sensitivity is low due to the occurrence of some grain growth at these high testing temperatures.
\end{abstract}

Keywords: CoCrFeNiMn; high-entropy alloy; high-pressure torsion; severe plastic deformation; superplasticity.

*Corresponding author. Tel.: +442380594438

E-mail address: H.Shahmir@soton.ac.uk 


\section{Introduction}

High entropy alloys (HEAs) are a new class of materials containing five or more principal elements with a simple crystal structure, such as an $f c c$ lattice, which show a potential combination of high solid solution strengthening and good ductility according to its solid solution phase [1,2]. One of the most studied single-phase HEAs is the equiatomic CoCrFeNiMn alloy [3-5]. The high temperature mechanical properties of this alloy were studied earlier but to date the occurrence of superplasticity has not been reported in this HEA [4,6-9]. It is well established that superplastic flow requires a very small grain size [10] and this may be achieved most readily through the application of severe plastic deformation (SPD) $[11,12]$. Processing by the SPD technique of high-pressure torsion (HPT) is especially effective in producing ultrafine grains [13] and this procedure has led to superplastic elongations in numerous metallic alloys $[14,15]$.

There are only a few reports describing the influence of HPT processing on HEAs [16-20] but it was shown for the CoCrFeNiMn alloy that processing by HPT leads to exceptional grain refinement to $\sim 10 \mathrm{~nm}$ with a significant strength of $\sim 1.75 \mathrm{GPa}$, a hardness of $\sim 4.41 \mathrm{GPa}$ and with a very low ductility of $\sim 4 \%$ at room temperature. No systematic investigations have been conducted to evaluate the high temperature mechanical behavior of this nanocrystalline CoCrFeNiMn alloy prepared by HPT. Accordingly, the present research was initiated to evaluate the effect of grain refinement due to HPT on the high temperature mechanical properties of the CoCrFeNiMn alloy. As will be demonstrated, this HEA is capable of exhibiting superplastic elongations of up to $>600 \%$ when testing in tension at a temperature of $973 \mathrm{~K}$.

\section{Experimental material and procedures}

An equiatomic CoCrFeNiMn (20 at.\% each element) alloy was prepared by arc-melting, casting into a bar and then homogenizing at $1273 \mathrm{~K}$ for $16 \mathrm{~h}$ in an Ar atmosphere: full details of the experimental procedure were given earlier [20]. Polished disks with diameters of $10 \mathrm{~mm}$ 
and thicknesses of $\sim 0.8 \mathrm{~mm}$ were prepared from the homogenized alloy and then processed by HPT for 5 turns at room temperature (RT) under an applied pressure of $6.0 \mathrm{GPa}$ at $1 \mathrm{rpm}$ using quasi-constrained conditions in which there is a small outflow of material around the periphery of the disk during the torsional straining [21]. Foils for transmission electron microscopy (TEM) were prepared after HPT processing using a focused ion beam (FIB) Zeiss Nvision 40 FIB facility at $3 \mathrm{~mm}$ from the disk centres in the normal sections of the disks so that the normal of the images lay in the shear direction. TEM micrographs were obtained using a JEOL JEM3010 microscope operating under an accelerating voltage of $300 \mathrm{kV}$.

Two miniature tensile specimens were cut from symmetric off-centre positions in each disk in order to avoid any inhomogeneities in the central regions of the disks [22]. These specimens were prepared by electro-discharge machining with gauge dimensions of $1.1 \times 1.0 \times 0.6 \mathrm{~mm}^{3}$ and the mechanical properties were examined at temperatures from 773 to $1073 \mathrm{~K}$. The stressstrain curves were recorded at each temperature using initial strain rates from $1.0 \times 10^{-3}$ to $1.0 \times$ $10^{-1} \mathrm{~s}^{-1}$ with at least two samples tested under each condition to ensure good reproducibility and with the testing conducted at constant displacement rates. The stress-strain curves were used to determine the ultimate tensile strengths (UTS) and the elongations to failure of each specimen with the elongations carefully checked by measuring the gauge lengths before and after tensile testing. Microstructural characterizations were conducted after testing by examining the gauge lengths and the gripping sections with optical microscopy (OM) and scanning electron microscopy (SEM). For the OM and SEM observations, the samples were ground through 800, 1200 and 4000 grit $\mathrm{SiC}$ papers, polished using a $40 \mathrm{~nm}$ colloidal silica suspension and then etched with a solution of $50 \mathrm{~mL} \mathrm{H}_{2} \mathrm{O}, 50 \mathrm{~mL} \mathrm{HCl}$ and $10 \mathrm{~g} \mathrm{CuSO}_{4}$.

\section{Experimental results}

A TEM micrograph and a selected area electron diffraction pattern (SAED) of the asprocessed CoCrFeNiMn HEA are shown in Fig. 1 at a region $\sim 3 \mathrm{~mm}$ from disk centre. The image shows that the microstructure of the HEA is highly strained with complicated non- 
uniform contrast because of the presence of a high density of different types of lattice defects. Many of the grains have irregular shapes with sharp corners and many grains are surrounded by wavy and not well-delineated boundaries. These diffuse boundaries are typical of materials prepared using SPD techniques and they are consistent with the presence of a large volume of high-energy non-equilibrium boundaries [23]. The equiaxed grains visible in Fig. 1 were formed by the fragmentation of elongated grains and it is apparent that the average size of the separate fragments of these structures is $\sim 10 \mathrm{~nm}$. The arrangement of the diffraction spots in semi-continuous circles in the SAED pattern confirms that the microstructure contains boundaries having high angles of misorientation and the appearance of significant streaking of diffraction spots indicates the presence of high internal stresses and elastic distortions of the crystal lattice. It is important to note that the observed diffraction pattern corresponds to the $f c c$ phase.

Figure 2(a) shows the engineering stress-elongation curves after tensile deformation at 773$1073 \mathrm{~K}$ with an initial strain rate of $1.0 \times 10^{-3} \mathrm{~s}^{-1}$. The results reveal an initial hardening followed by a peak and then gradual softening with the total elongations to failure increasing with increasing temperature up to $973 \mathrm{~K}$ and then decreasing. A complete set of curves is shown in Figs 2(b), (c) and (d) after tensile deformation at 873, 973 and $1073 \mathrm{~K}$, respectively, and it is apparent that the total elongation consistently increases with decreasing stain rate. The maximum total elongations recorded in these experiments exceed $600 \%$ and this confirms the occurrence of superplasticity which requires an elongation of at least $400 \%$ [10]. However, the experimental range of strain rates was not sufficient to reveal the three regions of flow generally associated with conventional superplastic alloys where the measured elongations decrease at both high and low strain rates [24].

Using the data from Fig. 2, Fig. 3(a) shows the flow stress plotted logarithmically against the strain rate where the stress values decrease with increasing temperature and decreasing 
strain rate. The measured value of the strain rate sensitivity, $m$, is $\sim 0.31$ over two orders of magnitude of strain rate.

In order to understand the mechanism controlling the superplastic deformation in the CoCrFeNiMn HEA, the following equation was utilized [25]:

$\dot{\varepsilon}=A\left(\frac{b}{d}\right)^{p}\left(\frac{\sigma}{G}\right)^{n} \exp \left(-\frac{\mathrm{Q}}{R T}\right)$

where $A$ is a constant, $\sigma$ is the flow stress, $G$ is the shear modulus, $n$ is the stress exponent which is equivalent to the reciprocal of the strain rate sensitivity $m, b$ is the Burgers vector, $d$ is the grain size, $p$ is the grain size exponent, $Q$ is the activation energy for deformation, $R$ is the gas constant and $T$ is the testing temperature. Figure 3(b) shows a semi-logarithmic plot of the strain rate against the inverse of the absolute temperature, $T$, for an applied stress, $\sigma$, of 200 MPa which is represented by the dashed line in Fig. 3(a) and this gives an experimental activation energy, $Q$, of $\sim 113 \mathrm{~kJ} \mathrm{~mol}^{-1}$.

Figures 4 shows the microstructures in the grip and gauge sections of the specimens deformed at $973 \mathrm{~K}$, where the strain rate was $1.0 \times 10^{-3} \mathrm{~s}^{-1}$, the tensile directions are marked as TD and the specimen correspond to the maximum tensile elongation of $\sim 610 \%$. The SEM observations in Fig 4(b-c) were undertaken at positions B and C within the gauge length and D within the gripping area as depicted in Fig. 4(a) where it is apparent that B lies very close to the fracture point of the specimens. The smooth nature of the gauge section in Fig. 4(a), and the lack of any incipient necking, is directly consistent with the requirements for superplastic flow [26].

Figure 5 shows the microstructures in the grip and gauge sections of the specimens deformed at $1073 \mathrm{~K}$ where Fig. 5(a) is an OM image of the fracture tip and the SEM image in (b) and OM images in (c) and (d) correspond to positions B, C and D as illustrated in Fig. 4(a). The strain rate was $1.0 \times 10^{-3} \mathrm{~s}^{-1}$ and the specimen corresponds to the maximum tensile elongation of $\sim 400 \%$. The EDS analyses of points marked as A-E are shown in (b). 
The possibility of grain boundary sliding (GBS) was examined in these experiments by inspection of the images in Figs 4 and 5. The images show there is a homogeneous equiaxed microstructure both in the undeformed grip regions and in the deformed gauge sections for the samples pulled at 973 and $1073 \mathrm{~K}$ with final grain sizes after deformation of $\sim 1.0$ and $\sim 5.5 \mu \mathrm{m}$, respectively. Thus, although these specimens failed at high elongations, there is no evidence for any elongated grains within the deformed microstructures and this is consistent with the occurrence of GBS and conventional superplasticity

A microstructural analysis of the sample tested at $973 \mathrm{~K}$ showed clearly the presence of precipitates in the matrix and some of these precipitates are marked by arrows in Fig. 4(b-d). It also appears that some precipitates were extracted from the matrix during etching. It was noted earlier that the CoCrFeNiMn alloy has a single-phase $f c c$ structure above $873 \mathrm{~K}$ but with a mixture of $f c c$ and $b c c$ phases below $873 \mathrm{~K}$ or, under some conditions, with a $\sigma$ phase which is an intermetallic compound having a tetragonal crystal structure [27]. An earlier study suggested that Cr-rich precipitates ( $b c c$ and $\sigma$ phases) are stable at $973 \mathrm{~K}$ [20]. Close inspection of Fig. 4 shows these precipitates are typically $\sim 300-600 \mathrm{~nm}$ in diameter and form along the grain boundaries which suggests they may act as obstacles to grain growth and therefore they are beneficial in maintaining a reasonably fine grain size. In Fig. 5, the microstructure of the sample tested at $1073 \mathrm{~K}$ shows small amounts of precipitates distributed within the grain interiors. It was noted earlier that the volume fraction of precipitated phases in this alloy decreases with increasing temperature and finally becomes negligible at $1073 \mathrm{~K}$ [20].

An SEM micrograph of the sample tested at $1073 \mathrm{~K}$ and the corresponding energy dispersive X-ray spectroscopy (EDS) analysis are presented in Fig. 5(b) where point A corresponds to the matrix. The grey phases marked as C and D in Fig. 5(b) were identified mainly as $\mathrm{Mn}$ and $\mathrm{Cr}$ oxides which probably form during deformation through in situ oxidation near the crack opening region since both $\mathrm{Cr}$ and $\mathrm{Mn}$ are strong oxide formers. This is consistent with earlier results where a coarse-grained CoCrFeNiMn HEA was examined after a low strain 
rate creep test at $1073 \mathrm{~K}$ [7]. By contrast, some coarser oxide particles, such as B and E in Fig. 5(b), were also present in the initial microstructure and are formed during alloying [20]. A relatively weak interface between these particles and the matrix probably promotes the formation of microcracks during tensile testing at $1073 \mathrm{~K}$ and this is consistent with the fracture tip shown in Fig. 5(a) where there is evidence for microcracking close to the fracture surface. This cracking at $1073 \mathrm{~K}$ will effectively reduce the elongations to failure as shown in Fig. 2(d).

\section{Discussion}

\subsection{Significance of the high temperature tensile results}

The present results indicate that the processing of the CoCrFeNiMn HEA by HPT through 5 turns at RT produces a grain size of $\sim 10 \mathrm{~nm}$ and this leads to superplastic elongations $(>400 \%)$ when testing at temperatures of 873 and $973 \mathrm{~K}$. The results presented in Fig. 2(c) show that the CoCrFeNiMn HEA shows superplasticity at $973 \mathrm{~K}$ even at initial strain rates of $\sim 1.0 \times 10^{-1} \mathrm{~s}^{-1}$ and the maximum total elongations recorded in these experiments exceed $600 \%$ at $973 \mathrm{~K}$ using an initial strain rate of $1.0 \times 10^{-3} \mathrm{~s}^{-1}$. The occurrence of superplasticity at a strain rate of $10^{-1} \mathrm{~s}^{-1}$ provides direct confirmation of the occurrence of high strain rate superplasticity in this material [28].

It has been reported that the high temperature mechanical behaviour of the coarse-grained CoCrFeNiMn alloy demonstrates typical dynamic recrystallization stress-strain curves with evidence for steady-state flow at temperatures above $1073 \mathrm{~K}$ whereas there is continuous strengthening below $1073 \mathrm{~K}$ [9]. Close inspection of the true stress-true strain curves in the present study revealed no evidence for any steady-state flow stress even at $1073 \mathrm{~K}$ and this suggests there is no dynamic recrystallization in the present experiments at least within the temperature range of $873-1073 \mathrm{~K}$.

Different activation energies of $\sim 291$ and $\sim 213 \mathrm{~kJ} \mathrm{~mol}^{-1}$ were reported for the coarsegrained CoCrFeNiMn HEA at temperatures above and below $1073 \mathrm{~K}$, respectively [9]. It is 
noted that the activation energy above $1073 \mathrm{~K}$ is comparable to the activation energy of $\sim 322$ $\mathrm{kJ} \mathrm{mol}^{-1}$ for grain growth in this alloy where Ni diffusion is rate-controlling [29]. In practice, it is well established that $\mathrm{Ni}$ is the element having the lowest diffusion coefficient in these HEAs [30]. An even higher activation energy of $\sim 330 \mathrm{~kJ} \cdot \mathrm{mol}^{-1}$ was obtained during tensile testing of the same alloy at temperatures above $1023 \mathrm{~K}$ using a strain rate of $>10^{-5} \mathrm{~s}^{-1}$ [7].

In the present experiments, the activation energy of $Q \approx 113 \mathrm{~kJ} \mathrm{~mol}^{-1}$ is much lower than the value of $\sim 213 \mathrm{~kJ} \mathrm{~mol}^{-1}$ for the coarse-grained alloy below $1073 \mathrm{~K}$ [9] but nevertheless the value is in excellent agreement with the activation energy of $\sim 115 \mathrm{~kJ} \mathrm{~mol}^{-1}$ reported for grain boundary diffusion in pure Ni [31]. This suggests that, as in conventional superplasticity [32], the rate of flow is controlled by grain boundary diffusion.

The advent of superplastic elongations and an activation energy close to the value for grain boundary diffusion suggests that GBS probably occurs in this alloy at these high temperatures [33]. For example, grain refinement during static recrystallization before tensile testing may facilitate the sliding and also reduce the effective stress and cause flow softening.

\subsection{Significance of the strain rate sensitivity in this alloy}

The analysis of the tensile testing given in Fig. 3(a) shows clearly that the flow stress decreases with increasing temperature and decreasing strain rate. Furthermore, the measured value of the strain rate sensitivity is $m \approx 0.3$ which is lower than the usual value of $m=0.5$ associated with superplastic flow [32]. This result appears instead to be consistent with the value of $m=0.3$ anticipated for flow where dislocation glide is the rate-controlling process [34]. Nevertheless, there is a clear dichotomy in these results that requires further analysis.

First, it is important to note there is excellent evidence for true superplastic flow in this CoCrFeNiMn alloy. Thus, the maximum elongation to failure exceeds $600 \%$ which readily fulfills the superplastic requirement of an elongations of at least $400 \%$, Fig. 4(a) shows there is no incipient necking within the gauge length at this high strain, the grains in Figs 4(b)-(d) are essentially equiaxed after tensile testing and the measured activation energy is consistent with 
the value for grain boundary diffusion of the element having the lowest diffusion coefficient. All of these results support the occurrence of true superplastic flow and yet the strain rate sensitivity is lower than anticipated for the superplastic mechanism.

To understand this discrepancy it is necessary to re-examine the results by comparing the present data with conventional superplastic alloys. In conventional alloys there is either no grain growth or only a very limited amount of grain growth occurring during testing but the HEA in these experiments is different because the grains grew substantially during the test that gave an elongation of $>600 \%$. Thus, the grain size immediately after HPT processing was only $\sim 10 \mathrm{~nm}$ but the final grain size after tensile testing at $973 \mathrm{~K}$ was $\sim 1.0 \mu \mathrm{m}$. This corresponds to an increase in grain size during tensile testing of two orders of magnitude and yet, because of the exceptionally small grain size after HPT processing, the final grain size remained within the superplastic regime.

A consideration of this result shows that the occurrence of substantial grain growth during testing will affect the measured strain rate sensitivity. This may be explained by examining the schematic illustration in Fig. 6 which shows, using logarithmic scales, the flow stress, $\sigma$, plotted against the initial strain rate, $\dot{\varepsilon}$, for a superplastic material having different values for the grain size, $d$. At high strain rates the results for all samples with different grain sizes fall on a single line because flow occurs by an intragranular dislocation process which is independent of grain size where this corresponds to region III in conventional superplastic alloys. But in the superplastic regime, corresponding to region II, the behavior depends on grain size such that the smallest grain size exhibits the fastest strain rate for any selected stress because in superplasticity the strain rate varies inversely with grain size raised to a power of 2 [31].

There are numerous experimental results in superplasticity showing the effect of grain size [35,36] and Fig. 6 depicts the possible trends for three different grain sizes. In tensile testing at constant displacement rates under conditions of grain growth, the values recorded for the flow stresses will depend on the instantaneous grain sizes when the stresses are recorded. In the 
absence of any grain growth, where the grain size remains constant throughout the test, three separate specimens may give the experimental points shown as solid circles in Fig. 6 with each point lying along a single line and with a slope corresponding to $m \approx 0.5$. But in the presence of significant grain growth, the experimental points will be displaced to lines appropriate for these larger grain sizes and the extent of this displacement will depend upon the amount of grain growth and therefore upon the time between the start of tensile testing and the recording of the flow stress. At lower strain rates this time will be longer and therefore there will be a tendency for the measured points at slow strain rates to move to the lines associated with larger grain sizes as depicted by the open points in Fig. 6. Thus, this displacement will produce an experimental value of $m$ which is lower than the true value so that the occurrence of grain growth in superplastic alloys can easily lead to an apparent strain rate sensitivity of $m \approx 0.3$.

This analysis provides an explanation for the occurrence of superplastic flow in the HEA even when the experimental value of the strain rate sensitivity is close to $\sim 0.3$ and it appears that dislocation glide may be the rate-controlling mechanism. It should be noted that there is also direct evidence that dislocation glide is not the rate-controlling mechanism in the present experiments because the measured elongations in dislocation glide are generally only about 200-300\% [37] and the highest elongation reported to date for any alloy undergoing flow by dislocation glide with $m \approx 0.3$ was slightly under $350 \%$ for an $\mathrm{Al}-5 \% \mathrm{Mg}$ alloy having a grain size of $40 \mu \mathrm{m}$ [38]. Indeed, this maximum elongation of $\sim 350 \%$ occurring in a coarse-grained material undergoing dislocation glide provided the impetus for delineating a minimum elongation of $400 \%$ in order to confirm the occurrence of true superplastic flow [10].

There are two basic requirements in order to achieve superplastic flow in a polycrystalline material [39]. First, the material must have a small and reasonably stable grain size which is smaller than $\sim 10 \mu \mathrm{m}$. This means superplasticity occurs in two-phase materials where the presence of separate phases leads to a significant inhibition of grain growth and in materials containing a fine dispersion of a second phase to act as a grain refiner. Second, superplasticity 
is diffusion-controlled and therefore it occurs only at temperatures at and above $\sim 0.5 T_{m}$ where $T_{m}$ is the absolute melting temperature of the material. The present results demonstrate that the grain sizes of the HPT-processed samples easily fulfill the requirement for superplasticity since the grain size is retained within the superplastic regime due to the presence of precipitates and the sluggish diffusion which is an inherent feature of these alloys [30,40]. Nevertheless, the formation of microcracks at the highest testing temperature of $1073 \mathrm{~K}$ leads to a deterioration in ductility at this temperature. In addition, the testing temperatures used to achieve superplasticity in this investigation are $>0.5 T_{m}$ based on the $\mathrm{CoCrFe}-\mathrm{NiMn}$ phase diagram where $T_{\mathrm{m}} \approx 1613 \mathrm{~K}[41]$.

Finally, the nanostructured CoCrFeNiMn HEA exhibits excellent ductility at 873-1073 K including superplastic elongations with a maximum elongation of $>600 \%$ at a testing temperature of $973 \mathrm{~K}$. This investigation therefore provides the first demonstration of superplasticity in the CoCrFeNiMn HEA. Although this result is unique for this alloy, superplastic elongations were reported earlier in the AlCoCrCuFeNi HEA [42-45] and this alloy exhibited a maximum elongation of $\sim 1240 \%$ when testing at a temperature of $1273 \mathrm{~K}$ [44]. In this latter HEA, the strain rate sensitivity was $m \approx 0.37-0.56$ which is higher than in the present HEA and generally consistent with the anticipated value of $m$ in superplastic flow.

\section{Summary and conclusions}

1. Processing of a CoCrFeNiMn HEA by HPT through 5 turns at RT produced a grain size of $\sim 10 \mathrm{~nm}$ and gave excellent ductility in tensile testing at $873-1073 \mathrm{~K}$ including superplastic elongations $(>400 \%)$ at temperatures of 873 and $973 \mathrm{~K}$. The maximum total elongation recorded in these experiments exceeded $600 \%$ at $973 \mathrm{~K}$.

2. The advent of superplastic elongations and an activation energy close to the value for grain boundary diffusion suggests that GBS occurs in this alloy at 873-1073 K. This is confirmed by the absence of any elongated grains within the microstructure after tensile testing and the lack of any incipient necking within the gauge length. 
3. The measured value of the apparent strain rate sensitivity was $\sim 0.3$ in these experiments but analysis shows this low value is due to the occurrence of significant grain growth during the tensile testing. It is concluded that the HEA does not deform by dislocation glide but rather it exhibits true superplastic flow when testing at elevated temperatures.

\section{Acknowledgments}

This work was supported in part by the National Natural Science Foundation of China (No. 51531001) (JYH and ZPL), in part by the NRF Korea funded by MoE (No. NRF2014R1A1A2057697 and NRF-2016R1A6A1A03013422) and by MSIP (No. NRF2016K1A4A3914691) (MK) and in part by the European Research Council under Grant Agreement No. 267464-SPDMETALS (HS and TGL). 


\section{References}

1. J.W. Yeh, S.K. Chen, S.J. Lin, J.Y. Gan, T.S. Chin, T.T. Shun, C.H. Tsau, S.Y. Chang, Nanostructured high-entropy alloys with multiple principal elements: novel alloy design concepts and outcomes, Adv. Eng. Mater. 6 (2004) 299-303.

2. B. Cantor, I.T.H. Chang, P. Knight, A.J.B. Vincent, Microstructural development in equiatomic multicomponent alloys, Mater. Sci. Eng. A 375-377 (2004) 213-218.

3. F. Otto, Y. Yang, H. Bei, E.P. George, Relative effects of enthalpy and entropy on the phase stability of equiatomic high-entropy alloys, Acta Mater. 61 (2013) 2628-2638.

4. F. Otto, A. Dlouhý, Ch. Somsen, H. Bei, G. Eggeler, E.P. George, The influences of temperature and microstructure on the tensile properties of a $\mathrm{CoCrFeMnNi}$ high-entropy alloy, Acta Mater. 61 (2013) 5743-5755.

5. B. Gludovatz, A. Hohenwarter, D. Catoor, E.H. Chang, E.P. George, R.O. Ritchie, A fracture-resistant high-entropy alloy for cryogenic applications, Science 345 (2014) 11531158.

6. A. Gali, E.P. George, Tensile properties of high- and medium-entropy alloys, Intermetallics 39 (2013) 74-78.

7. J.Y. He, C. Zhu, D.Q. Zhou, W.H. Liu, T.G. Nieh, Z.P. Lu, Steady state flow of the FeCoNiCrMn high entropy alloy at elevated temperatures, Intermetallics 55 (2014) 9-14.

8. Z. Wu, H. Bei, G.M. Pharr, E.P. George, Temperature dependence of the mechanical properties of equiatomic solid solution alloys with face-centered cubic crystal structures, Acta Mater. 81 (2014) 428-441.

9. N.D. Stepanov, D.G. Shaysultanov, N.Yu. Yurchenko, S.V. Zherebtsov, A.N. Ladygin, G.A. Salishchev, M.A. Tikhonovsky, High temperature deformation behavior and dynamic recrystallization in CoCrFeNiMn high entropy alloy, Mater.Sci.Eng. A 636 (2015) 188-195. 
10. T.G. Langdon, Seventy-five years of superplasticity: Historic developments and new opportunities, J. Mater. Sci. 44 (2009) 5998-6010.

11. R.Z. Valiev, R.K.Islamgaliev, I.V. Alexandrov, Bulk nanostructured materials from severe plastic deformation, Prog. Mater. Sci. 45 (2000) 103-189.

12. T.G. Langdon, Twenty-five years of ultrafine-grained materials: Achieving exceptional properties through grain refinement, Acta Mater. 61 (2013) 7035-7059.

13. A.P. Zhilyaev, T.G. Langdon, Using high-pressure torsion for metal processing: Fundamentals and applications, Prog. Mater. Sci. 53 (2008) 893-979.

14. M. Kawasaki, T.G. Langdon, Review: achieving superplasticity in metals processed by high-pressure torsion, J. Mater. Sci. 49 (2014) 6487-6496.

15. M. Kawasaki, T.G. Langdon, Review: achieving superplastic properties in ultrafinegrained materials at high temperatures, J. Mater. Sci. 51 (2016) 19-32.

16. Q.H. Tang, Y. Huang, Y.Y. Huang, X.Z. Liao, T.G. Langdon, P.Q. Dai, Hardening of an $\mathrm{Al}_{0.3} \mathrm{CoCrFeNi}$ high entropy alloy via high-pressure torsion and thermal annealing, Mater. Lett. 151 (2015) 126-129.

17. B. Schuh, F. Mendez-Martin, B. Völker, E.P. George, H. Clemens, R. Pippan, A. Hohenwarter, Mechanical properties, microstructure and thermal stability of a nanocrystalline CoCrFeMnNi high-entropy alloy after severe plastic deformation, Acta Mater. 96 (2015) 258-268.

18. D-H. Lee, I-C. Choi, M-Y. Seok, J. He, Z. Lu, J-Y. Suh, M. Kawasaki, T.G. Langdon, JI. Jang, Nanomechanical behavior and structural stability of a nanocrystalline CoCrFeNiMn high-entropy alloy processed by high-pressure torsion, J. Mater. Res. 30 (2015) 2804-2815.

19. P.F. Yu, H. Cheng, L.J. Zhang, H. Zhang, Q. Jing, M.Z. Ma, P.K. Liaw, G. Li, R.P. Liu, Effects of high pressure torsion on microstructures and properties of an $\mathrm{Al}_{0.1} \mathrm{CoCrFeNi}$ high-entropy alloy, Mater. Sci. Eng. A655 (2016) 283-291. 
20. H. Shahmir, J.Y. He, Z.P. Lu, M. Kawasaki, T.G. Langdon, Effect of annealing on mechanical properties of a nanocrystalline $\mathrm{CoCrFeNiMn} \mathrm{high-entropy} \mathrm{alloy} \mathrm{processed} \mathrm{by}$ high-pressure torsion, Mater. Sci. Eng. A676 (2016) 294.

21. R.B. Figueiredo, P.R. Cetlin, T.G. Langdon, Using finite element modeling to examine the flow processes in quasi-constrained high-pressure torsion, Mater. Sci. Eng. A528 (2011) 8198-8204.

22. A. Loucif, R.B. Figueiredo, M. Kawasaki, T. Baudin, F. Brisset, R. Chemam, T.G. Langdon, Effect of aging on microstructural development in an $\mathrm{Al}-\mathrm{Mg}-\mathrm{Si}$ alloy processed by high-pressure torsion, J. Mater. Sci. 47 (2012) 7815-7820.

23. J. Wang J, Z. Horita, M. Furukawa, M. Nemoto, N.K. Tsenev, R.Z. Valiev, Y. Ma, T.G. Langdon, An investigation of ductility and microstructural evolution in an $\mathrm{Al}-3 \% \mathrm{Mg}$ alloy with submicron grain size, J. Mater. Res. 8 (1993) 2810-2818.

24. H. Ishikawa, F.A. Mohamed, T.G. Langdon, The influence of strain rate on ductility in the superplastic Zn-22\% Al eutectoid, Phil. Mag. 32 (1975) 1269-1271.

25. O.D. Sherby, J. Wadsworth, Superplasticity-Recent advances and future directions, Prog. Mater. Sci. 33 (1989) 169-221.

26. T.G. Langdon, Fracture processes in superplastic flow, Metal Sci. 16 (1982) 175-183.

27. F. Zhang, C .Zhang, S.L. Chen, J. Zhu, W.S. Cao, U.R. Kattner, An understanding of high entropy alloys from phase diagram calculations, CALPHAD 45 (2014) 1-10.

28. K. Higashi, M. Mabuchi, T.G. Langdon, High-strain-rate superplasticity in metallic materials and the potential for ceramic materials, ISIJ Intl. 36 (1996) 1423-1438.

29. W.H. Liu, Y. Wu, J.Y. He, T.G. Nieh, Z.P. Lu, Grain growth and the Hall-Petch relationship in a high-entropy FeCrNiCoMn alloy, Scr. Mater. 68 (7) (2013) 526-529.

30. K.Y. Tsai, M.H. Tsai, J.W. Yeh, Sluggish diffusion in $\mathrm{Co}-\mathrm{Cr}-\mathrm{Fe}-\mathrm{Mn}-\mathrm{Ni}$ high-entropy alloys, Acta Mater. 61 (2013) 4887-4897. 
31. A.R. Wazzan, Lattice and grain boundary self-diffusion in nickel, J. Appl. Phys. 36 (1965) 3596-3599.

32. T.G. Langdon, A unified approach to grain boundary sliding in creep and superplasticity, Acta Metall. Mater. 42 (1994) 2437-2443.

33. T.G. Langdon, An evaluation of the strain contributed by grain boundary sliding in superplasticity, Mater. Sci. Eng. A174 (1994) 225-230.

34. F.A. Mohamed, T.G. Langdon, The transition from dislocation climb to viscous glide in creep of solid solution alloys, Acta Metall. 22 (1974) 779-788.

35. G. Rai, N.J. Grant, On the measurements of superplasticity in an Al-Cu alloy, Metall. Trans. 6A (1975) 385-390.

36. F.A. Mohamed, T.G. Langdon, Creep behaviour in the superplastic Pb-62\% Sn eutectic, Phil. Mag. 32 (1975) 697-709.

37. F.A. Mohamed, Creep ductility in large-grained solid solution alloys, Scripta Metall. 12 (1978) 99-102.

38. M. Otsuka, S. Shibasaki, M. Kikuchi, Superplasticity in coarse grained Al-Mg alloys, Mater. Sci. Forum 233-234 (1997) 193-198.

39. T.G. Langdon, The mechanical properties of superplastic materials, Metall. Trans. 13A (1982) 689-701.

40. S.Y. Chang, C.E. Li, Y.C. Huang, H.F. Hsu, J.W. Yeh, S.J. Lin, Structural and thermodynamic factors of suppressed interdiffusion kinetics in multi-component highentropy materials, Sci. Reports 4 (2014) 4162.

41. M. Laurent-Brocq, A. Akhatova, L. Perrière, S. Chebini, X. Sauvage, E. Leroy, Y. Champion, Insights into the phase diagram of the CrMnFeCoNi high entropy alloy, Acta Mater. 88 (2015) 355-365. 
42. A.V. Kuznetsov, D.G. Shaysultanov, N.D. Stepanov, G.A. Salishchev, O.N. Senkov, Tensile properties of an $\mathrm{AlCrCuNiFeCo}$ high-entropy alloy in as-cast and wrought conditions, Mater. Sci. Eng. A533 (2012) 107-118.

43. A.V. Kuznetsov, D.G. Shaysultanov, N.D. Stepanov, G.A. Salishchev, O.N. Senkov, Superplasticity of AlCoCrCuFeNi high entropy alloy, Mater. Sci. Forum 735 (2013) 146151.

44. D.G. Shaysultanov, N.D. Stepanov, A.V. Kuznetsov, G.A. Salishchev, O.N. Senkov, Phase composition and superplastic behavior of a wrought AlCoCrCuFeNi high-entropy alloy, JOM 65 (2013) 1815-1828.

45. N.D. Stepanov, D.G. Shaysultanov. G.A. Salishchev, O.N. Senkov, Mechanical behavior and microstructure evolution during superplastic deformation of the fine-grained AlCoCrCuFeNi high entropy alloy, Mater. Sci. Forum 838-839 (2016) 302-307. 


\section{Figures captions:}

Fig. 1 TEM image and corresponding SAED pattern for the CoCrNiFeMn high-entropy alloy after 5 turns of HPT processing at $1 \mathrm{rpm}$.

Fig. 2 Engineering stress-elongation curves for samples processed by HPT through 5 revolutions: (a) curves at different temperatures at an initial strain rate of $1.0 \times 10^{-3} \mathrm{~s}^{-1}$ and curves at (b) $873 \mathrm{~K}$, (c) $973 \mathrm{~K}$ and (d) $1073 \mathrm{~K}$ at initial strain rates of $1.0 \times 10^{-3}$ to $1.0 \times 10^{-1} \mathrm{~s}^{-1}$. Fig. 3 (a) Flow stress plotted against initial strain rate to determine the strain rate sensitivity, $m$, and (b) strain rates at $200 \mathrm{MPa}$ (dashed line in (a)) plotted against reciprocal of temperature to determine the activation energy.

Fig. 4. (a) Sample after tensile testing at $973 \mathrm{~K}$ with initial strain rate of $1.0 \times 10^{-3} \mathrm{~s}^{-1}$ corresponding to the maximum elongation of $\sim 610 \%$ : SEM micrographs in (b), (c) and (d) correspond to positions B, C and D shown in (a): the arrows denote precipitates and the tensile directions (TD) are indicated.

Fig. 5. OM and SEM micrographs of the sample after tensile testing at $1073 \mathrm{~K}$ with an initial strain rate of $1.0 \times 10^{-3} \mathrm{~s}^{-1}$ corresponding to an elongation of $\sim 400 \%$ : (a) is an OM image of the fracture tip and the SEM images in (b), (c) and (d) correspond to positions B, C and D as illustrated in Fig. 4(a): the EDS analyses of points marked as A-E are shown in (b) and the tensile directions (TD) are indicated.

Fig. 6. Schematic illustration of flow stress against strain rate showing the effect of grain size on superplasticity and the potential for recording an exceptionally low value for the strain rate sensitivity (open points) in the presence of grain growth. 


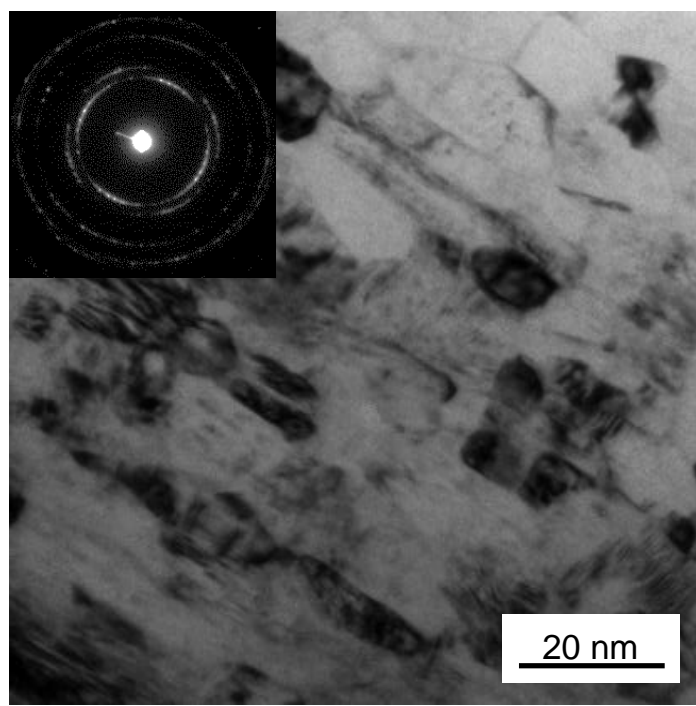

Fig. 1 TEM image and corresponding SAED pattern for the CoCrNiFeMn high-entropy alloy after 5 turns of HPT processing at $1 \mathrm{rpm}$. 

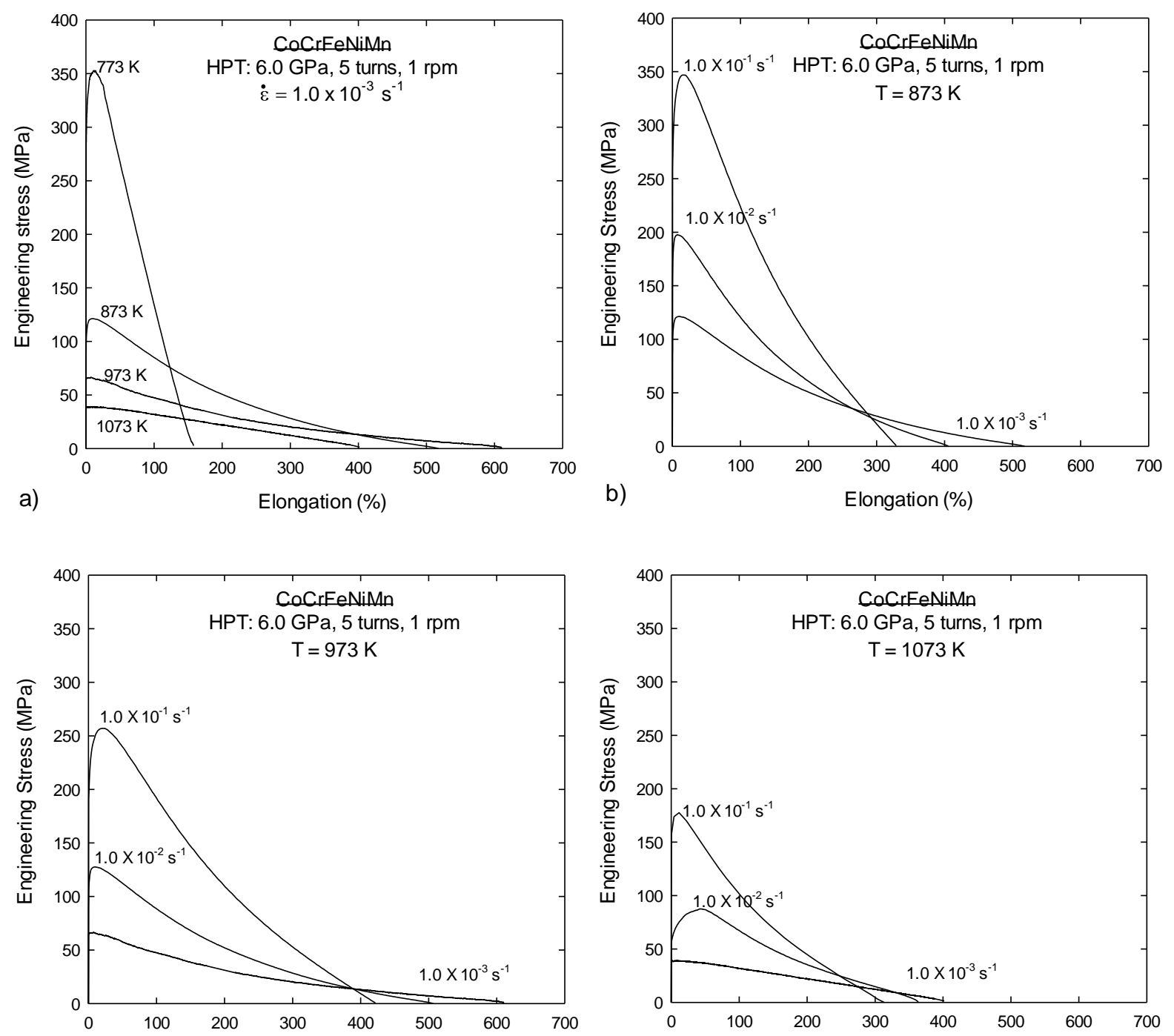

c)

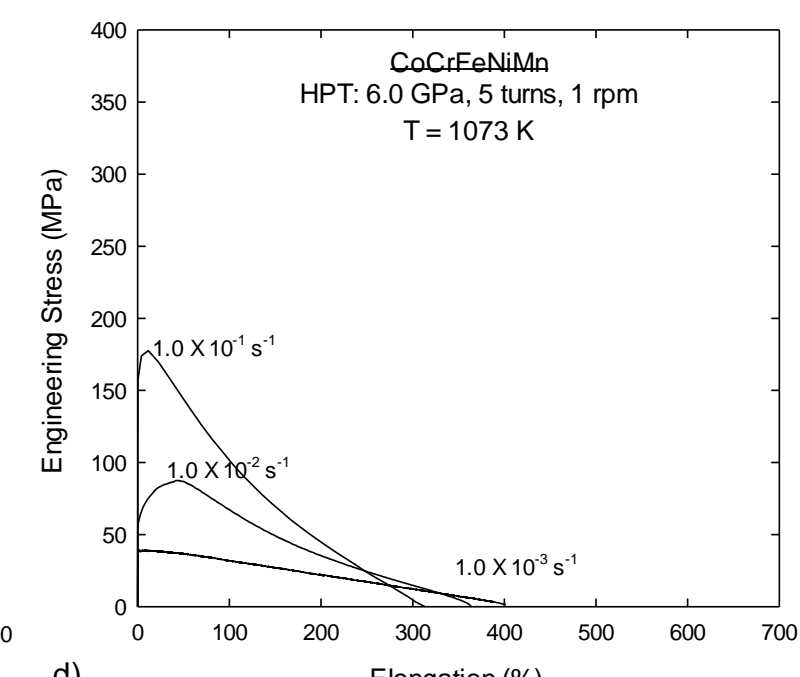

Fig. 2. Engineering stress-elongation curves for samples processed by HPT through 5 revolutions:

(a) curves at different temperatures at an initial strain rate of $1.0 \times 10^{-3} \mathrm{~s}^{-1}$ and curves at (b) $873 \mathrm{~K}$, (c) $973 \mathrm{~K}$ and (d) $1073 \mathrm{~K}$ at initial strain rates of $1.0 \times 10^{-3}$ to $1.0 \times 10^{-1} \mathrm{~s}^{-1}$. 


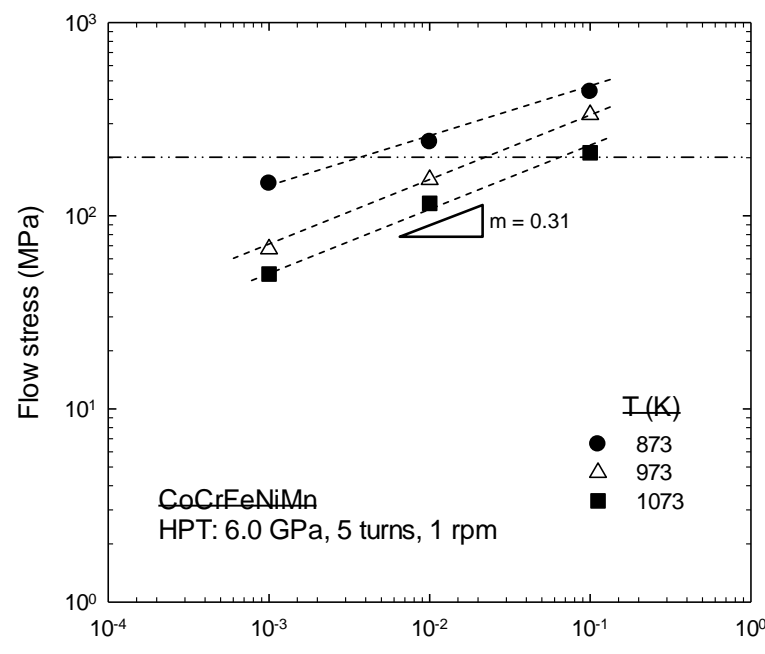

a)

Strain rate $\left(s^{-1}\right)$

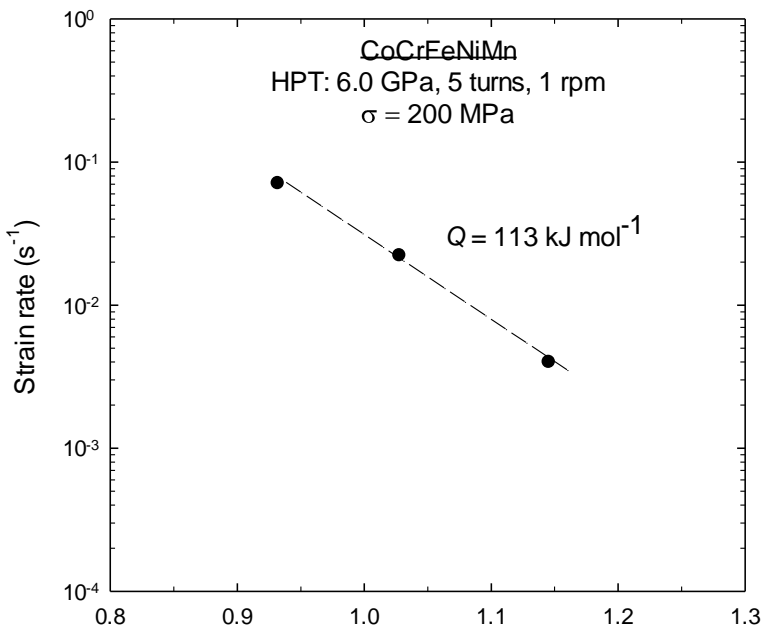

b)

$1 / \mathrm{T}\left(10^{-3} \mathrm{~K}^{-1}\right)$

Fig. 3 (a) Flow stress plotted against initial strain rate to determine the strain rate sensitivity, $m$, and (b) strain rates at $200 \mathrm{MPa}$ (dashed line in (a)) plotted against reciprocal of temperature to determine the activation energy. 

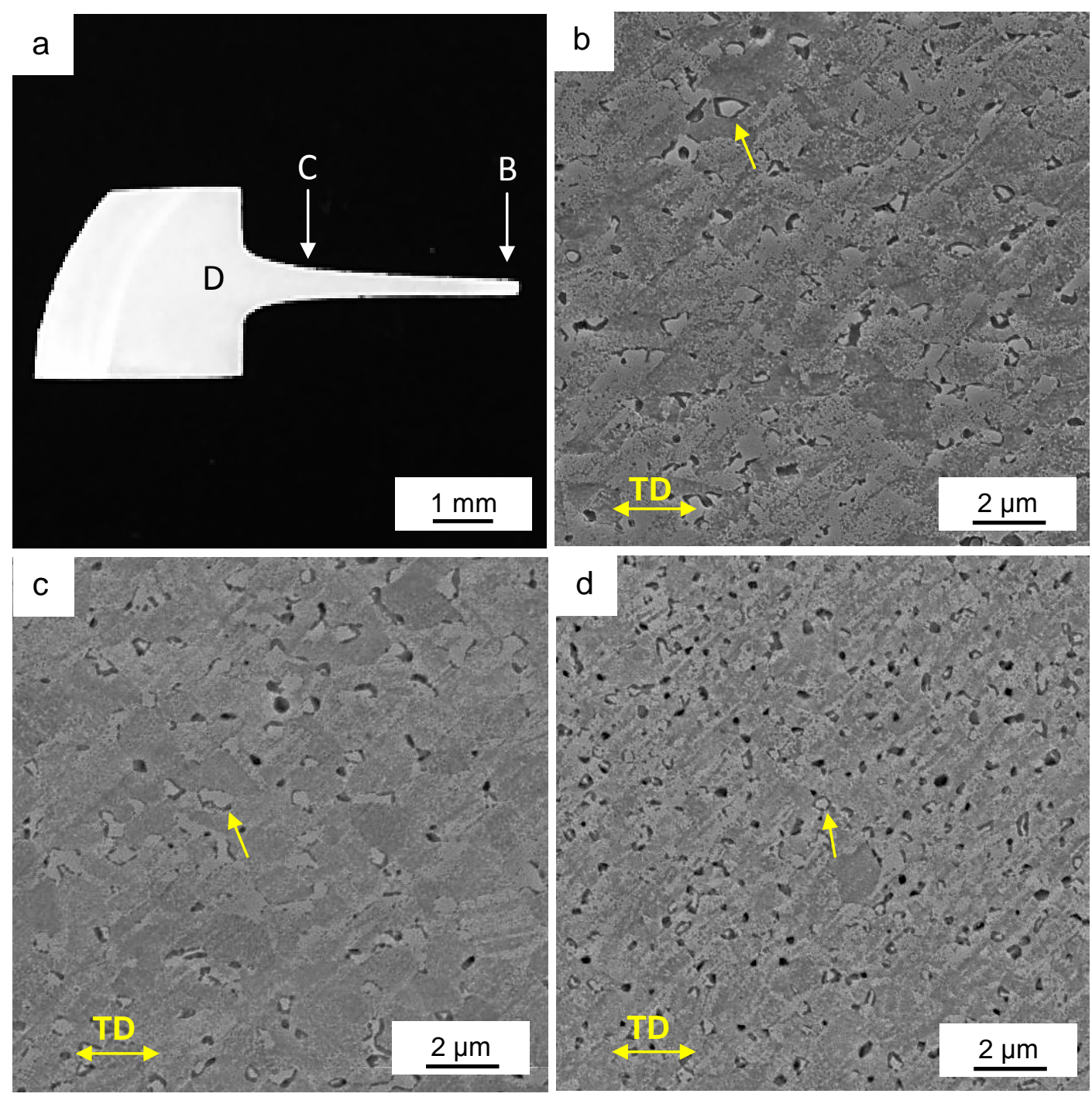

Fig. 4. (a) Sample after tensile testing at $973 \mathrm{~K}$ with initial strain rate of $1.0 \times 10^{-3} \mathrm{~s}^{-1}$ corresponding to the maximum elongation of $\sim 610 \%$ : SEM micrographs in (b), (c) and (d) correspond to positions

$\mathrm{B}, \mathrm{C}$ and $\mathrm{D}$ shown in (a): the arrows denote precipitates and the tensile directions (TD) are indicated. 

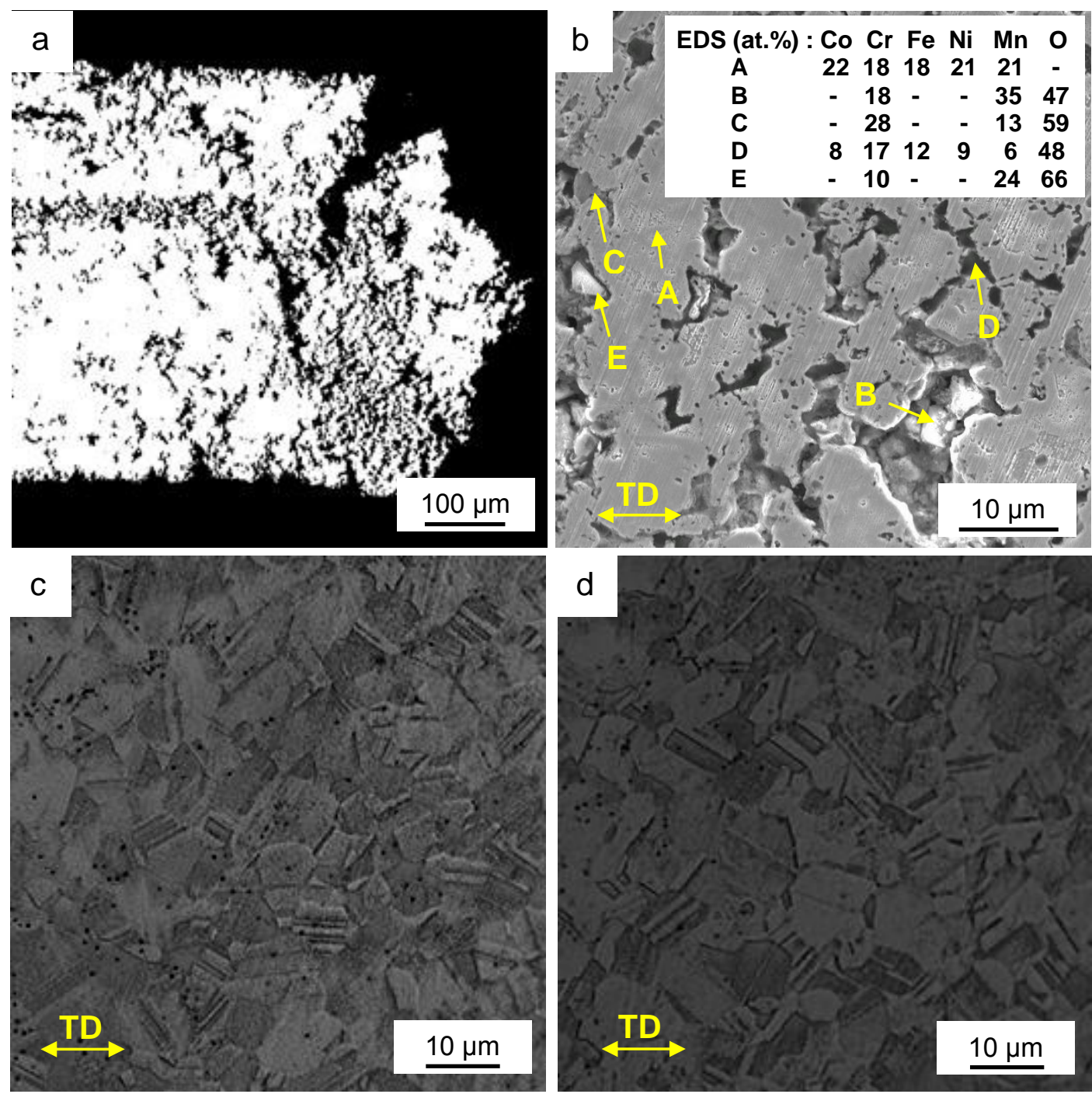

Fig. 5. OM and SEM micrographs of the sample after tensile testing at $1073 \mathrm{~K}$ with an initial strain rate of $1.0 \times 10^{-3} \mathrm{~s}^{-1}$ corresponding to an elongation of $\sim 400 \%$ : (a) is an OM image of the fracture tip and the SEM images in (b), (c) and (d) correspond to positions B, C and D as illustrated in Fig. 4(a): the EDS analyses of points marked as A-E are shown in (b) and the tensile directions (TD) are indicated. 


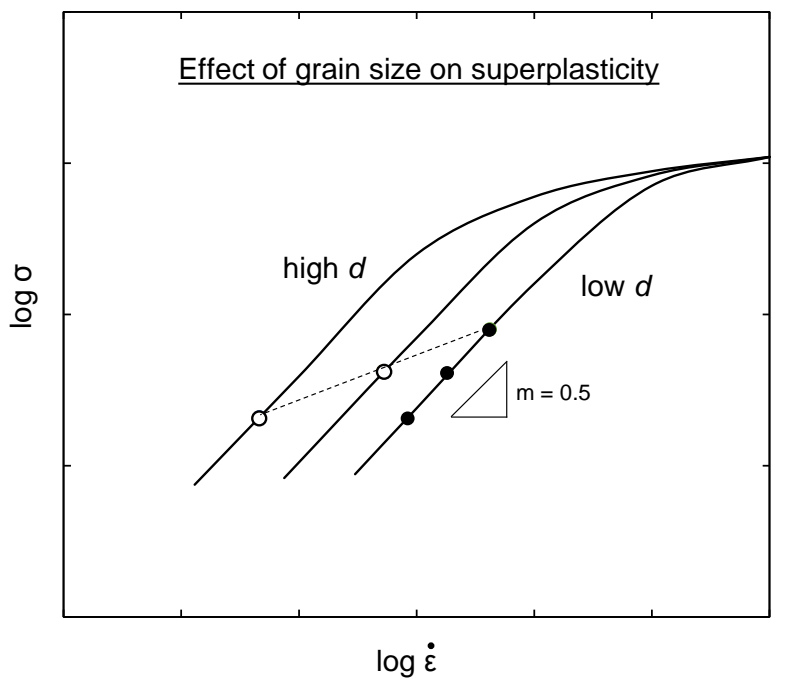

Fig. 6. Schematic illustration of tlow stress against strain rate showing the effect of grain size on superplasticity and the potential for recording an exceptionally low value for the strain rate sensitivity (open points) in the presence of grain growth. 